\title{
Accessing gelling ability of vegetable proteins using rheological and fluorescence techniques
}

\author{
Ana Paula Batista ${ }^{\mathrm{a}}$, Carla A.M. Portugal ${ }^{\mathrm{b}}$, Isabel Sousa ${ }^{\mathrm{c}}$, \\ João G. Crespo ${ }^{\mathrm{b}}$, Anabela Raymundo ${ }^{\mathrm{a}, *}$ \\ a CIEAB, Instituto Piaget-ISEIT de Almada, Quinta da Arreinela de Cima, 2800-305 Almada, Portugal \\ ${ }^{\mathrm{b}}$ Requimte-Departamento de Química, CQFB, Faculdade de Ciencias e Tecnologia, Universidade Nova de Lisboa, 2829-516 Caparica, Portugal \\ c Secção de Ciência e Tecnologia dos Alimentos/DAIAT-Instituto Superior de Agronomia, Tapada da Ajuda, 1349-017 Lisboa, Portugal
}

Received 14 April 2004; received in revised form 8 April 2005; accepted 8 April 2005

Available online 5 July 2005

\begin{abstract}
This work aims to present a comprehensive study about the macroscopic characteristics of globular vegetable proteins, in terms of their gelling ability, by understanding their molecular behaviour, when submitted to a thermal gelling process. The gels of soy, pea and lupin proteins were characterized by rheological techniques. Gelation kinetics, mechanical spectra, as well as the texture of these gels were analyzed and compared. Additionally, capillary viscometry, steady-state fluorescence and fluorescence anisotropy were used to monitor the structural changes induced by the thermal denaturation, which constitutes the main condition for the formation of a gel structure. Based on these techniques it was possible to establish a relationship between the gelling ability of each protein isolate and their structural resistance to thermal unfolding, enabling us to explain the weakest and the strongest gelling ability observed for lupin and soy proteins isolates, respectively. (C) 2005 Elsevier B.V. All rights reserved.
\end{abstract}

Keywords: Vegetable proteins; Gels; Intrinsic viscosity; Rheology; Steady-state fluorescence; Fluorescence anisotropy

\section{Introduction}

The use of vegetable proteins in food products, as an alternative to animal proteins, is a subject of growing interest [1]. Legume seed proteins, besides their nutritional properties, have gained additional importance on modern food design as a consequence of their favourable functional properties [2]. They have been studied as successful replacers for animal proteins in food foams [3-4] and emulsions [5-8].

The development of food gels as dairy desserts, using globular proteins from plant seeds to fully replace the egg and milk sources, has been recently studied [9-10]. The potential of these vegetable proteins to form a stable network like a gel structure should be related to their molecular properties, namely their ability to unfold, which can be enhanced by a certain degree of thermal denaturation. Gel formation by globular proteins is a complex process, which

\footnotetext{
* Corresponding author. Tel.: +35121294 62 69; fax: +351 212941584 . E-mail address: araymundo@almada.ipiaget.org (A. Raymundo).
}

often involves several reactions such as molecular unfolding, dissociation-association, and aggregation [11]. In the Ferry classical review on biopolymer gelation [12], globular protein gels were considered to be based on side-by-side associations of highly unfolded peptide chains. Therefore, the main condition to form a gel structure is the unfolding of the protein molecule. During the thermal denaturation process the native protein conformation becomes unfolded, exposing the functional groups (such as sulfhydryl or hydrophobic groups). Consequently, an aggregation process due to the formation of disulfide bonds and hydrophobic interactions between these groups may take place [13], in order to minimize the energy of the system. When the protein concentration is above its critical gelling point, aggregation may lead to formation of a gel structure [14].

In the present work, lupin, pea, and soy proteins were gelled in model conditions and were characterized according to their rheological behaviour and texture properties. The gelling behaviour described by the macroscopic techniques, in terms of texture and viscoelastic properties, was better 
understood using results from insight methods such as capillary viscometry and fluorescence techniques.

Therefore, in order to identify alterations undergone in the molecular structures of these protein isolates upon thermal treatment, the changes of their intrinsic viscosity values were determined by capillary viscometry. This parameter is a measure of the hydrodynamic volume of a molecule in a given solvent, and can provide information concerning the protein conformation and an indication of the ability of the protein to unfold and take up water, in diluted systems [15].

The structural modifications of the proteins observed were supported and complemented by measurements performed by steady-state fluorometry and fluorescence anisotropy. These fluorometry techniques allowed for the identification of the unfolded state achieved by each protein isolate, during and after heating [16]. These additional studies enabled us to establish a correspondence between the unfolded state and the gelling ability of each protein isolate.

\section{Materials and methods}

\subsection{Materials}

Three protein isolates from leguminous seeds were used: pea isolate (Pisane HD, Cosucra, Belgium), lupin isolate (LupiE, Fraunhofer Inst., Germany) and soy isolate (S974, ADM, Netherlands). These materials were all kindly provided by the respective manufacturers.

\subsection{Methods}

\subsubsection{Gelling behaviour assessed by rheological characterization}

2.2.1.1. Preparation of gels. The protein isolates were dispersed in demineralised water at $\mathrm{pH} 5.5$, under magnetic stirring $(1 \mathrm{~h})$ at room temperature. The concentrations used were $10 \%(\mathrm{w} / \mathrm{w})$ for the soy protein isolate, 12.5 and $16 \%$ $(\mathrm{w} / \mathrm{w})$ for the pea protein isolate and $16 \%(\mathrm{w} / \mathrm{w})$ for the lupin protein isolate.

These suspensions were heated-up to $90{ }^{\circ} \mathrm{C}$ for $15 \mathrm{~min}$ in order to assure protein unfolding which results in the reinforcement of the gel structure $[10,17]$. Immediately after the suspensions were poured into $6 \mathrm{~cm}$ diameter cylindrical containers, filled up to $3.5 \mathrm{~cm}$ height. Gels were allowed to set at a temperature of $5-7^{\circ} \mathrm{C}$, in the refrigerator, for texture analysis. For rheological measurements, the heated suspensions were immediately poured into the rheometer measuring system.

2.2.1.2. Texture measurements. The texture parameter firmness $(N)$, considered as the maximum resistance to the penetration of the probe, was the unique parameter with discriminating ability to compare gels. It was calculated as the height of the force peak during the first compression cycle, from the texture profile analysis (TPA) curve, using a TA-XT2
(Stable Micro Systems, UK) texturometer. Penetration tests were performed with a $25 \mathrm{~mm}$ diameter cylindrical probe in gels contained in cylindrical glass flasks of $60 \mathrm{~mm}$ diameter and $45 \mathrm{~mm}$ height $(10 \mathrm{~mm}$ penetration, $5 \mathrm{~s}$ waiting time and $2 \mathrm{~mm} / \mathrm{s}$ crosshead speed). The experiments were carried out $24 \mathrm{~h}$ after preparation of the gels. Before performing any measurements, gels were allowed to equilibrate at $20^{\circ} \mathrm{C}$ for approximately $3 \mathrm{~h}$ in a temperature-controlled room. The measurements for each sample were performed three times.

2.2.1.3. Rheological measurements. Rheological measurements were performed using a controlled-stress rheometer (RS-75, Haake, Germany) with a cone and plate geometry (cone diameter $35 \mathrm{~mm}$, angle $2^{\circ}$ ).

The heated protein suspensions were placed in the rheometer measuring device, which was pre-heated at $40^{\circ} \mathrm{C}$, and cooled down to $5^{\circ} \mathrm{C}$ at $0.6^{\circ} \mathrm{C} / \mathrm{min}$. It was practically impossible to monitor gelation in the measuring device above $90^{\circ} \mathrm{C}$, since at this temperature the protein dispersions were too fluid to be analyzed by our rheometer, whose minimum stress value is of the order of $0.5 \mathrm{~Pa}$, and at such high temperatures it was also difficult to maintain the required cooling rate.

The maturation of the gels was monitored during $24 \mathrm{~h}$ at $5{ }^{\circ} \mathrm{C}$. Gelation kinetics was followed, by using oscillatory measurements, at constant stress $(0.5 \mathrm{~Pa})$ and frequency (1 Hz).

Structure was measured in terms of rheological parameters-storage modulus $\left(G^{\prime}\right)$ accounting for the elastic component of the material and loss modulus $\left(G^{\prime \prime}\right)$ describing the viscous component. The values of $G^{\prime}$ and $G^{\prime \prime}$ were plotted against time, and the equilibrium was expressed by the independence of these viscoelastic functions over time.

After the maturation period, without disturbing the gel structure, frequency sweeps were conducted at $5^{\circ} \mathrm{C}$, with oscillation frequencies ranging from 0.01 to $115.6 \mathrm{rad} / \mathrm{s}$. A constant shear stress, within the linear viscoelastic region of the material, was used in all measurements.

Frequency sweeps are the mechanical spectra of the material at constant stress and temperature. From the feature of these spectra it is possible to characterize the internal structure of the gels, which for certain type of spectra can be expressed by the plateau modulus $\left(G_{\mathrm{N}}^{0}\right)$. These structures are characterized by the development of an entangled network among the protein molecules as a physical reinforcement of the primary gel network. The plateau modulus can be easily estimated as the value of $G^{\prime}$ obtained for the minimum value of the loss tangent $\left(\tan \delta=G^{\prime \prime} / G^{\prime}\right)$, expressed as [18]:

$G_{\mathrm{N}}^{0}=\left[G^{\prime}\right]_{\tan \delta \rightarrow \operatorname{minimum}}$

For all rheological experiments the samples on the rheometer were covered with a layer of paraffin oil to prevent moisture loss. All measurements were repeated three times.

Statistical analysis, ANOVA/MANOVA, post hoc comparisons-Scheffe test, was performed using the Software Statistica (version 5.0, Statsoft Inc., USA). 


\subsubsection{Determination of the hydrodynamic volume of the protein molecules by capillary viscometry}

Protein isolates were dispersed in demineralised water, under magnetic stirring $(30 \mathrm{~min})$ at room temperature. The concentrations used were sufficiently diluted to show Newtonian behaviour $(0.05-0.60 \mathrm{~g} / \mathrm{ml})$.

The viscosity of these solutions was measured by capillary viscometry, before and after a thermal treatment at $90^{\circ} \mathrm{C}$ during $15 \mathrm{~min}$. An automatic viscosity measuring unit AVS 450 (Schott-Gerate, Germany), with an Ubbelhode capillary viscometer (size Ic, constant $=0.03$, Schott-Gerate, Germany) was used. The viscometer was immersed in a water bath to maintain the temperature at $25 \pm 0.1^{\circ} \mathrm{C}$. The Hagenbach correction for the kinetic energy was automatically introduced by the equipment processor.

The intrinsic viscosity ([ $\eta]$ ) of the solutions was calculated from the capillary viscosity data by fitting the Huggins (2) and Kraemer (3) equations in a double-extrapolation plot:

$\eta_{\text {red }}=[\eta]+k_{\mathrm{H}}[\eta]^{2} \times c$

$\ln \left(\frac{\eta_{\mathrm{r}}}{c}\right)=[\eta]-k_{\mathrm{k}}[\eta]^{2} \times c$

where $\eta_{\mathrm{red}}$ is the reduced viscosity $\left.\left(\left(\eta-\eta_{\mathrm{s}}\right) / \eta_{\mathrm{s}} \times c\right)\right)$; $\eta_{\mathrm{r}}$ is the relative viscosity $\left(\eta / \eta_{\mathrm{s}}\right) ; \eta$ is the solution viscosity; $\eta_{\mathrm{s}}$ is the solvent viscosity; $c$ is the protein concentration; $k_{\mathrm{H}}$ and $k_{\mathrm{K}}$ are the Huggins and Kraemer constants.

For density determinations of the solutions an analytical balance (XB-220, Precisa, Switzerland) coupled to a density kit was used, at the same temperature.

\subsubsection{Monitoring the protein gelling process using fluorescence techniques}

2.2.3.1. Preparation of protein samples. The appearance of turbidity in protein isolates solutions prevented us from using protein concentrations higher than $0.05 \%(\mathrm{w} / \mathrm{w})$, which was far from the critical gelling concentration point. The turbidity increment occurred due to the presence of water insoluble materials in the protein isolates, such as ash and fats, or even to the presence of protein aggregates formed due to the pretreatment steps applied (e.g. protein isolation processes) by the manufacturer. The turbidity alters the optical behaviour of the isolates solutions contributing to the decrease of fluorescence intensity, due to an increase of scattering phenomena, and consequently to the inclusion of additional errors on the fluorescent measurements.

Moreover, the fluorescence experiments were performed not to monitor the aggregation process, but to study the molecular mechanisms (folding/unfolding), induced by the thermal treatment, which enables us to explain the differences of gelling ability for the three protein isolates. These studies were only possible if the aggregation process do not occur.

Therefore, in order to avoid these effects, the solutions of pea, soy and lupin protein isolates were prepared in a concentration of $0.05 \%(\mathrm{w} / \mathrm{w})$, at $\mathrm{pH} 5.5$ in demineralised water.
2.2.3.2. Steady-state fluorescence spectra acquisition. These solutions were heated in a block heater (Stuart Scientific) at $90^{\circ} \mathrm{C}$, for $15 \mathrm{~min}$, (the same temperature used for the protein gelling processing). Afterwards they were left to cool down at room temperature, $25^{\circ} \mathrm{C}$.

The steady-state fluorescence spectra were acquired, for each protein solution, before and after heating, both at $25^{\circ} \mathrm{C}$, using a Luminescence Spectrometer (Perkin Elmer, LS-5B). These spectra were acquired by scanning the proteins solutions at a fixed excitation wavelength $\left(\lambda_{\text {exc }}\right)$ of $280 \mathrm{~nm}$ and ranging the emission wavelengths $\left(\lambda_{\mathrm{em}}\right)$ from 305 to $400 \mathrm{~nm}$.

The alterations, induced by heating, on the protein structures were perceived by calculating the relative fluorescence intensity differences, RFID. This value was obtained by subtracting the fluorescence intensity of the protein solution after heating, $\mathrm{FI}_{\mathrm{A}}$, from the fluorescence intensity of the protein solution before heating, $\mathrm{FI}_{\mathrm{B}}$, according to Eq. (4):

$\mathrm{RFID}=\frac{\mathrm{FI}_{\mathrm{B}}-\mathrm{FI}_{\mathrm{A}}}{\mathrm{FI}_{\mathrm{B}}} \times 100$

The protein molecules may present three amino acids, which are able to produce fluorescence emission: tryptophan, tyrosine, and phenylalanine. However, the presence of neighbouring quenchers, such as aspartate, glutamate, or cysteines, which enable the formation of hydrogen or disulfide bonds with or nearby the fluorophore, can suppress their fluorescence emission intensity. Therefore, as tryptophan is the fluorophore with the highest quantum yield, it is usually the only fluorophore detected in the protein fluorescence spectra. Consequently, fluorescence spectra of proteins are typically characterized by the presence of a unique peak, located in the region of spectra ascribed to tryptophan, at a maximum excitation wavelength of $280 \mathrm{~nm}$ and a maximum emission wavelength of $350 \mathrm{~nm}$. The emission of tryptophans can then be influenced either by their relative distance to quenchers, or by the polarity of the environment in their vicinity, which alters the efficiency of the quenching effect over them. Therefore, it is expected that the alterations induced in the protein structure may promote the relocation of some of the quenchers, and/or variations in the polarity felt by the tryptophans due to their different exposure to the solvent, leading to changes in the fluorescence spectra of the proteins.

\subsubsection{Steady-state fluorescence anisotropy measurements.} Fluorescence anisotropy values were measured at a fixed $\lambda_{\text {exc }}$ of $280 \mathrm{~nm}$ and a fixed $\lambda_{\mathrm{em}}$ of $350 \mathrm{~nm}$. The fluorescence anisotropy measurements were performed in triplicate using a spectrofluorimeter SPEX 212 I Fluorolog, according to two different procedures. In the first procedure the fluorescence anisotropy was measured before and after heating the protein solutions (both at $25^{\circ} \mathrm{C}$ ); the second procedure consisted in measuring the fluorescence anisotropy at different temperatures in a range from 25 to $90^{\circ} \mathrm{C}$. This last procedure was achieved by using a thermostatic cell holder, which was coupled to a temperature controller. The values of fluorescence anisotropy presented, correspond to the average 
of three measurements performed for each sample, for the different temperature values.

The fluorescence anisotropy technique allows the detection of alterations on the mobility of the fluorophores present in the protein chain and is expressed by the following equation:

$R=\frac{\text { polarized light }}{\text { total light }}=\frac{I_{\|}-I_{\perp}}{I_{\|}+2 I_{\perp}}$

where $I_{\|}$is the fluorescence intensity acquired when the excitation and emission polarizers are oriented in parallel and $I_{\perp}$ is the fluorescence intensity acquired when both polarizers are perpendicularly oriented.

According to Eq. (5), fluorescence anisotropy, $R$, is the fraction of polarized light $\left(I_{\|}-I_{\perp}\right)$ emitted by a molecule when excited by a polarized light beam. In the presence of a fully isotropic solution the intensity of the light emitted parallel to the excitation light will be equal to the intensity of light emitted perpendicularly to the excitation light. Therefore, the numerator of Eq. (5) is cancelled and correspondently the anisotropy, $R$, equals to zero. Otherwise, the emitted light can be depolarized due to the rotational diffusion of the fluorophores present in molecules, such as proteins. Therefore, modifications of the protein structure, may induce changes of the fluorophores free rotation, and consequently may alter the fraction of polarized light emitted by them. An increase of the fluorescence anisotropy is due to a decrease of rotational freedom (decrease of mobility) of the fluorophores and corresponds to higher molecular packing or a molecular aggregation. On the opposite, a decrease in the fluorescence anisotropy is related to a higher mobility of the fluorophores, corresponding to a molecular unfolding.

\section{Results and discussion}

\subsection{Gelling ability of soy, pea and lupin protein isolates}

The three vegetable protein isolates that were studied present distinct characteristics. Pea and Soy isolates are produced industrially, being submitted to rather severe processing conditions, while lupin isolate is produced at a lab-scale, under mild processing conditions. It was necessary to use different concentrations of protein isolates to assure proper dissolution and gelation. In fact, it was not possible to disperse (at room temperature) more than $10 \%(\mathrm{w} / \mathrm{w})$ of the soy protein isolate, which formed a consistent gel at this concentration. However, at this concentration no gelation occurred for the pea and lupin isolate. To overcome this limitation, it was decided to compare soy and pea protein gels prepared at lower concentrations $(10-12.5 \%, \mathrm{w} / \mathrm{w})$ and to compare pea and lupin protein gels at higher concentrations $(16 \%, \mathrm{w} / \mathrm{w})$.

Moreover, it was observed that when using $10 \%$ of soy protein, the gel obtained showed significantly higher rheological characteristics than the pea protein gel prepared with a higher protein concentration (12.5\%). When comparing pea and lupin at $16 \%$ protein concentration, the pea protein gel presented higher rheological parameter values than lupin, reflecting a higher degree of internal structure.

Even when using different protein concentrations, due to the reasons stated above, it was possible to conclude that the soy protein isolate presented higher gelling ability than the pea protein, which, in turn, was better than the lupin protein isolate.

For pea protein isolate there was no gel formation at $10 \%$ $(\mathrm{w} / \mathrm{w})$ and at $12.5 \%(\mathrm{w} / \mathrm{w})$ gelation occurred in the rheometer measuring device but not in the refrigerator, as a result of the different cooling rate profiles [19-20]. The cooling profile provided by the refrigerator could not be controlled, but the objective was also to compare in situ controlled-rate gelification with "industrial" gel setting conditions on the gels properties.

This indicates that we are probably in the limitingconcentration for gelation to occur. For all the rheological and textural parameters studied, the soy protein gel presented higher values than the pea protein gel, although a lower protein concentration was used.

The heating of the lupin protein suspensions resulted in high viscous materials which can be regarded as poor gels (weak) since $G^{\prime}$ was slightly higher than $G^{\prime \prime}$. Nevertheless, variations on the viscoelastic functions of these lupin structures with temperature decrease were not observed, as it was observed for pea and soy gels. Due to the reasons presented, the cooling and maturation curves of the $16 \%(\mathrm{w} / \mathrm{w})$ lupin and pea protein systems are not represented.

Fig. 1 presents the cooling curves of the soy and pea protein gels. The sol-gel transition was not detected, since it should have occurred at higher temperatures, between 90 and $40{ }^{\circ} \mathrm{C}$. In previous studies [17], in which the gelation of a lupin protein isolate dispersion $(20 \%$, w/w) was monitored from 75 to $5{ }^{\circ} \mathrm{C}$, the sol-gel was not observed. This fact may indicate that the sol-gel transition for these materials occurs at higher temperatures, above $75^{\circ} \mathrm{C}$.

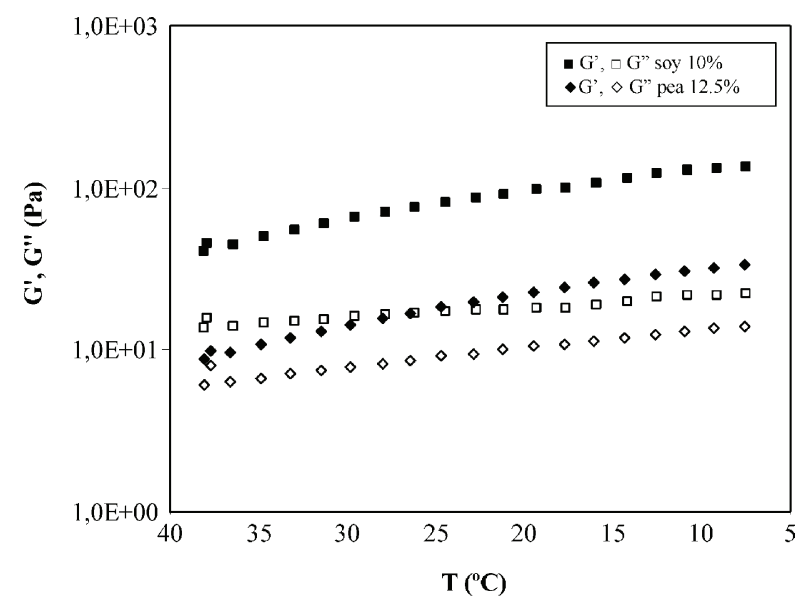

Fig. 1. Evolution of $G^{\prime}$ and $G^{\prime \prime}$ values upon cooling from 40 to $5^{\circ} \mathrm{C}$ of $10 \%$ $(\mathrm{w} / \mathrm{w})$ soy protein and $12.5 \%(\mathrm{w} / \mathrm{w})$ pea protein suspensions. 


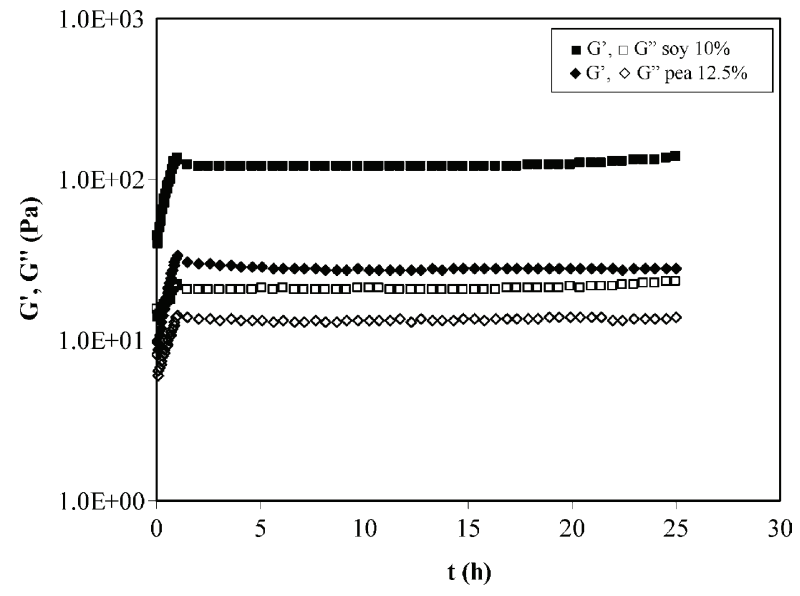

Fig. 2. Maturation kinetic curves of $10 \%(\mathrm{w} / \mathrm{w})$ soy protein and $12.5 \%(\mathrm{w} / \mathrm{w})$ pea protein gels, at $5^{\circ} \mathrm{C}$.

A larger gap between $G^{\prime}$ and $G^{\prime \prime}$ can be observed for the soy protein, evidencing the development of a gel structure stronger than for the pea protein gel. Cooling from 40 to $5^{\circ} \mathrm{C}$ resulted in a slight increase of the viscoelastic moduli $\left(G^{\prime}\right.$ and $G^{\prime \prime}$ ) of the gels. Rapid gel maturation occurred (Fig. 2), i.e. after $2.5 \mathrm{~h}$ the gel structure was stabilized. These are rapid set gels, with gelation temperatures above $40^{\circ} \mathrm{C}$.

In Fig. 3 it is possible to compare the mechanical spectra of the soy and pea protein gels cooled in the rheometer measuring device and in the refrigerator. The soy protein gel presented the highest viscoelastic parameters. Moreover, no significant differences were observed for the plateau modulus $\left(G_{\mathrm{N}}^{0}\right)$ of soy protein gels gellified in the rheometer (average $95 \mathrm{~Pa}$ ) and in the refrigerator (average $111 \mathrm{~Pa}$ ), considering a probability minor than $0.05(p<0.05)$. For the pea protein, gellified in the rheometer plate, the formation of a weak gel structure was observed, with a strong $G^{\prime}$ and $G^{\prime \prime}$ frequency dependence. For the pea protein dispersion, cooled in the refrigerator, no gel formation occurred, and a

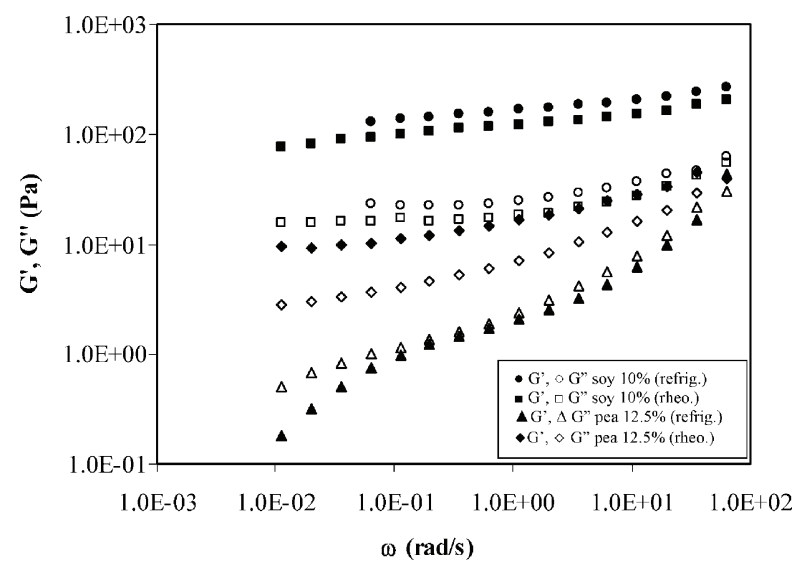

Fig. 3. Mechanical spectra of $10 \%(\mathrm{w} / \mathrm{w})$ soy protein and $12.5 \%(\mathrm{w} / \mathrm{w})$ pea protein gels cooled in the rheometer measuring device and on the refrigerator, at $5{ }^{\circ} \mathrm{C}$.

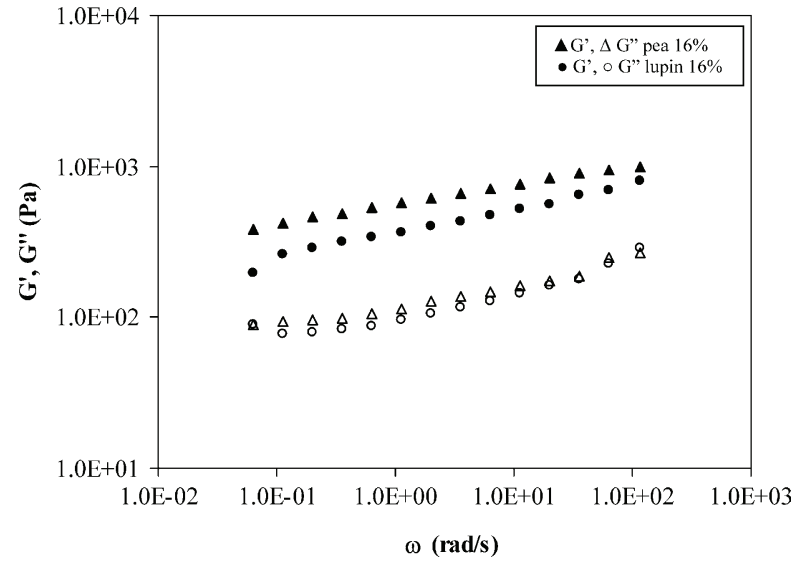

Fig. 4. Mechanical spectra of $16 \%(\mathrm{w} / \mathrm{w})$ pea protein and lupin protein systems, at $5^{\circ} \mathrm{C}$.

high dependence of the viscoelastic functions with frequency was also observed, accompanied by values of $\tan \delta$ above one, meaning the domination of the viscous component. The use of different cooling rate profiles was much more relevant for the pea than for the soy protein gelation, probably because the pea protein concentration used was around the critical point for the gel formation.

Comparing now the lupin with pea protein solutions at a higher concentration $(16 \%, \mathrm{w} / \mathrm{w})$, it can be observed that both pea and lupin systems presented a typical weak gellike structure, i.e. $G^{\prime}$ is always higher than $G^{\prime \prime}$ (one order of magnitude) for the whole frequency range studied, with both moduli being slightly frequency dependent (Fig. 4). There were no significant differences $(p<0.05)$ for the plateau modulus results between pea and lupin protein systems at $16 \%$ (w/w) concentration (average 457 and $349 \mathrm{~Pa}$, respectively).

The results of the texture analysis were in agreement with the previous rheological results (Fig. 5). The soy protein gel at $10 \%(\mathrm{w} / \mathrm{w})$ showed an average firmness of $1.23 \mathrm{~N}$. For the pea and lupin gels at $16 \%(\mathrm{w} / \mathrm{w})$ the values of firmness were

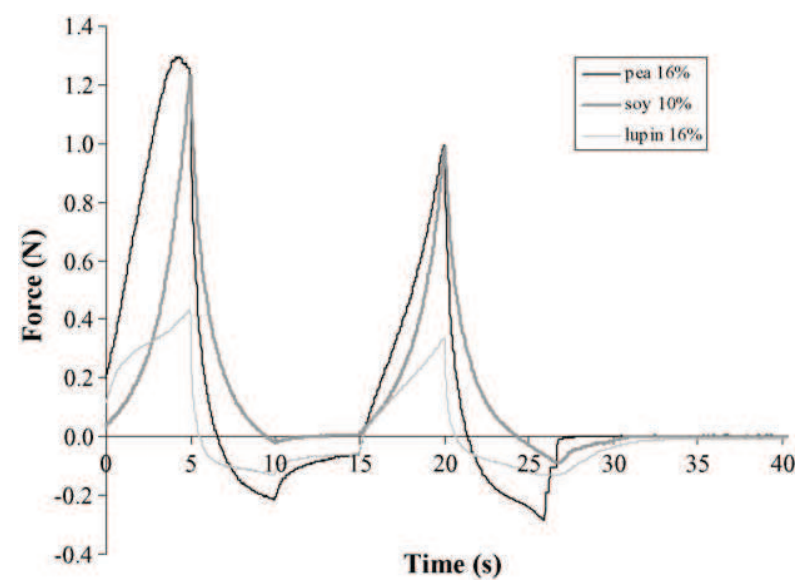

Fig. 5. Texturograms force vs. time of soy $(10 \%, \mathrm{w} / \mathrm{w})$, pea $(16 \%, \mathrm{w} / \mathrm{w})$ and lupin $(16 \%, \mathrm{w} / \mathrm{w})$ protein systems. 


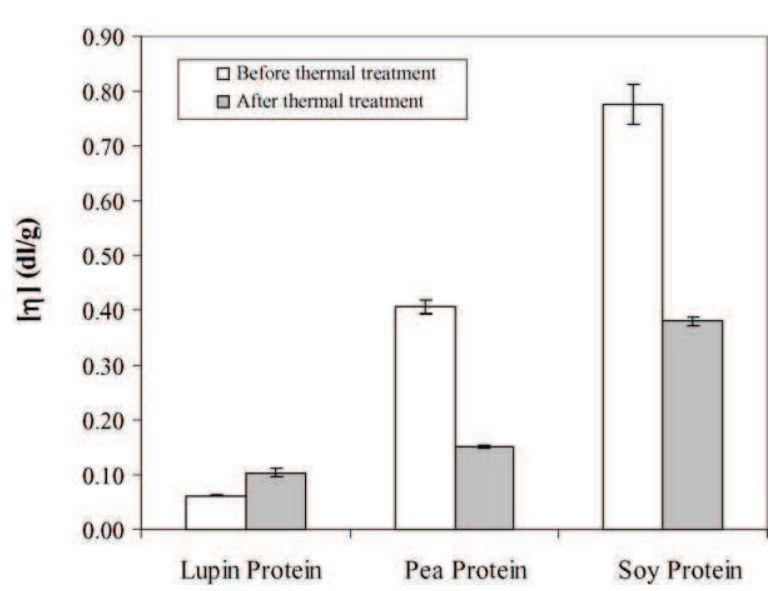

Fig. 6. Intrinsic viscosity values for the lupin, pea and soy protein isolates in aqueous solutions at $25^{\circ} \mathrm{C}$, before and after a thermal treatment at $90{ }^{\circ} \mathrm{C} / 15 \mathrm{~min}$.

1.34 and $0.43 N$, respectively. This macroscopic characterization of the gels shows that soy protein is able to form a gel structure at a concentration as low as $10 \%(\mathrm{w} / \mathrm{w})$ that is comparable with pea gels at a concentration of $16 \%(\mathrm{w} / \mathrm{w})$, in terms of their texture parameters. In addition these two gels are significantly $(p<0.05)$ firmer than the lupin system at a concentration as high as $16 \%(\mathrm{w} / \mathrm{w})$.

Texture measurements allowed a better discrimination between the different protein gel structures formed. Although the mechanical spectra have evidenced a weak gel-like structure for lupin and pea, the texture measurements allowed perceiving that lupin showed a lack of structure characteristic of a poor gel system.

\subsection{Determination of the hydrodynamic volume of the protein molecules by capillary viscometry}

The intrinsic viscosity $([\eta])$ average results for the three protein isolates studied, before and after a thermal treatment at $90{ }^{\circ} \mathrm{C}$ during $15 \mathrm{~min}$ are represented in Fig. 6. These averages values are obtained by the adjustment of the Huggins and Kraemer equations to the experimental points, according to the procedure described in Section 2.2.2. Most globular proteins in their native state have intrinsic viscosities of approximately $0.025-0.060 \mathrm{dl} / \mathrm{g}$ [21-22]. For the three isolates studied, only the lupin protein showed an intrinsic viscosity within this range of $0.055-0.070 \mathrm{dl} / \mathrm{g}$ for the Huggins and Kraemer equation, respectively (average $0.062 \mathrm{dl} / \mathrm{g}$ ) at $25^{\circ} \mathrm{C}$. When this isolate was submitted to the thermal treatment, the intrinsic viscosity increased up to 0.089 and $0.120 \mathrm{dl} / \mathrm{g}$ for the Huggins and Kraemer equation, respectively (average $0.105 \mathrm{dl} / \mathrm{g}$ ). This increase of the intrinsic viscosity was associated with a loss of the native structure of this protein and consequent formation of a random coil-like structure, leading to an increase of the molecular hydrodynamic volume of the lupin protein, as expected [23].
The pea protein isolate presented an intrinsic viscosity of 0.405 and $0.408 \mathrm{dl} / \mathrm{g}$ for the Huggins and Kraemer equation, respectively (average $0.406 \mathrm{dl} / \mathrm{g}$ ) at $25^{\circ} \mathrm{C}$. After thermal treatment this value was reduced down to $0.153-0.154 \mathrm{dl} / \mathrm{g}$ (Huggins and Kraemer equation results). The initially higher intrinsic viscosity values may be explained by the existence of protein association, which accounts for the higher values of the hydrodynamic values for these small aggregates. When these flow units are subjected to heat exposure, energy can be used to break the aggregates, resulting in a lower hydrodynamic volume of these units. The values of intrinsic viscosity, after the thermal treatment, compare well with the values of the heat-denatured lupin protein. This feature can also be observed in the case of the soy protein isolate, which exhibits larger intrinsic viscosity values of $0.762 \mathrm{dl} / \mathrm{g}$ for the Huggins and $0.788 \mathrm{dl} / \mathrm{g}$ for the Kraemer equation (average of $0.775 \mathrm{dl} / \mathrm{g}$ ) before heating. As a result of the thermal treatment, these values were reduced down to $0.389 \mathrm{dl} / \mathrm{g}$ for the Huggins and $0.375 \mathrm{dl} / \mathrm{g}$ for the Kraemer equation (average of $0.382 \mathrm{dl} / \mathrm{g})$.

After the thermal treatment, lupin protein isolate exhibits an intrinsic viscosity value smaller than the pea and soy protein isolates which means that for the lupin protein, the unfolding was less pronounced than for pea and soy proteins, confirming its weak gelling ability and according to previous DSC studies [24].

It is well known that a severe exposure of soy and pea proteins to a steam stream is used for the destruction of the anti-trypsin and other anti-nutrient factors. Lupin protein does not show these anti-nutrient disadvantages, therefore the isolate is not steamed, and this could be the reason for such a distinct molecular behaviour of the proteins in dilute solution. Nevertheless, a direct relation between the intrinsic viscosity and gelling ability was observed, i.e. higher values of intrinsic viscosity are related with a higher capacity to form a stable gel structure.

\subsection{Assessing the gelling ability by using fluorescence techniques}

The differences in fluorescence intensity obtained for pea, soy and lupin protein isolates are depicted in Fig. 7, which shows that the heating treatment induces a decrease in the fluorescence intensity of the three protein isolates. It can also be perceived that the structural alterations undergone by pea and soy isolates led to identical changes in the fluorescence intensities, laying between 50 and 30\% in the whole range of the scanned emission wavelengths. The relative fluorescence intensity differences, observed for the lupin isolate presented a smaller magnitude, between 30 and $15 \%$ in the same $\lambda_{\text {em }}$ range, evidencing that the molecular structure of lupin proteins was less susceptible to alteration, when subjected to heating. The differences in fluorescence intensity are due to alterations of the fluorophores microenvironment. It may correspond to an alteration of the protein tri-dimensional structure (size-to-shape relation) or simply 


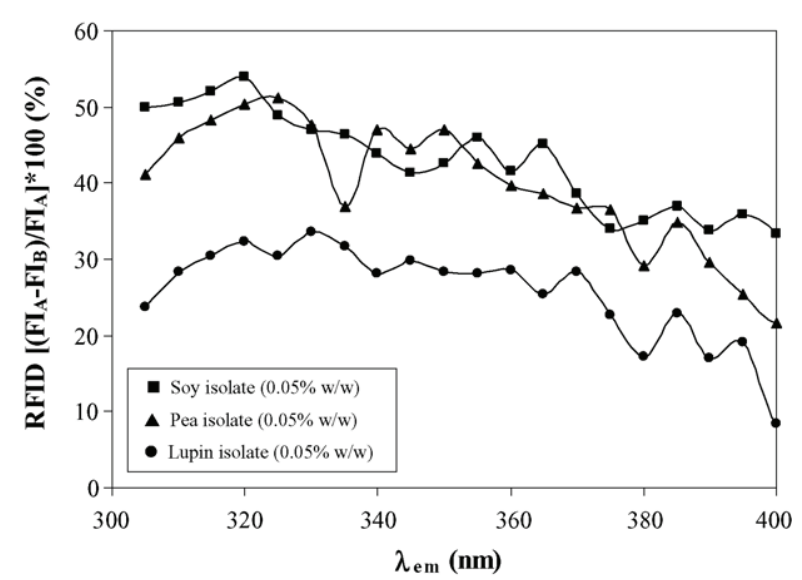

Fig. 7. Intensity fluorescence differences (RFID) acquired for soy, pea and lupin protein isolates $(0.05 \%, \mathrm{w} / \mathrm{w})$ upon heating at $90^{\circ} \mathrm{C}$. The fluorescence measurements were performed at $25^{\circ} \mathrm{C}$ and $\lambda_{\text {exc }}=280 \mathrm{~nm}$.

to the fluorophores reorientation towards other amino acids, which may not involve changes of the overall proteins tridimensional structure.

Since alterations of the proteins tri-dimensional structure are associated to modifications in fluorophores mobility, measurements of fluorescence anisotropy were performed to complement the steady-state fluorescence results.

The fluorescence anisotropy data obtained are listed in Table 1. The results show that after heating the anisotropy fluorescence of each protein isolate decreases. This behaviour is associated with the increase of the proteins mobility, which may reflect the disruption of the protein associations in the initial solutions, as previously explained, as well as their unfolding, due to the thermal heating applied. Comparing the fluorescence anisotropy differences for soy and pea, before and after heating, it is possible to perceive that they decrease in the same extent, suggesting that the unfold increment was similar for both protein isolates. The smaller fluorescence anisotropy difference observed for lupin indicates that heating induces minor alterations on the lupin tri-dimensional structure, therefore confirming its weak gelling ability, which are in accordance to the fluorescence intensity differences obtained and explains the weak gelling ability found for lupin protein isolate.

The ability of a protein to gellify is strongly dependent on the molecular unfolding state reached during heating and on the tendency of each protein molecule to aggregate during the cooling phase. The proteins aggregation process is thermodynamically ruled, being characterized by a loss in entropy that must be compensated by an enthalpy gain in order to minimize the Gibbs energy of the system. Moreover,

Table 1

Fluorescence anisotropy values acquired at $25^{\circ} \mathrm{C}$, before and after heating at $90^{\circ} \mathrm{C}$, for $15 \mathrm{~min}$

\begin{tabular}{llll}
\hline & Soy isolate & Pea isolate & Lupin isolate \\
\hline Before heating & $0.146 \pm 0.018$ & $0.076 \pm 0.003$ & $0.089 \pm 0.004$ \\
After heating & $0.101 \pm 0.006$ & $0.054 \pm 0.006$ & $0.085 \pm 0.003$ \\
\hline
\end{tabular}

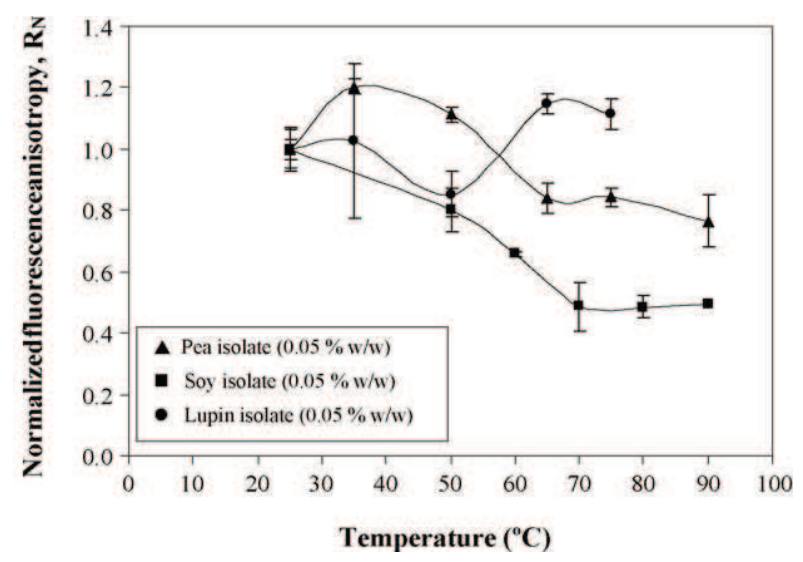

Fig. 8. Normalized fluorescence anisotropy $\left(R_{\mathrm{N}}\right)$ acquired for soy, pea and lupin protein isolates $(0.05 \%, \mathrm{w} / \mathrm{w})$ at different temperatures, at $\lambda_{\mathrm{exc}}=280 \mathrm{~nm}$ and $\lambda_{\mathrm{em}}=350 \mathrm{~nm}$.

the capacity of each protein molecule to aggregate depends on the environmental ( $\mathrm{pH}$ and ionic strength) and on the processing conditions, namely the cooling temperature profile and the protein concentration [9].

The protein concentration used in these experiments $(0.05 \%, \mathrm{w} / \mathrm{w})$ is more than 100 times lower than the concentration needed for the gelation of these vegetable proteins to occur (in the order of 10-15\%). Attending to this we consider that for the solutions used in fluorescence studies the concentration was well below the critical gelling point, so the aggregation mechanisms were not perceived, and a gellike structure was not obtained for any of the protein isolates. Instead, the refolding mechanism dominates throughout the cooling process, masking the unfolding degree acquired by the protein molecules during heating. To overcome this setback, alterations of the proteins structure were also monitored by fluorescence anisotropy, during thermal treatment, at different temperatures in a range from 25 to $90^{\circ} \mathrm{C}$.

Fig. 8 presents the normalized fluorescence anisotropy values obtained, which were calculated according to the following expression:

$R_{\mathrm{N}}=\frac{R_{T}}{R_{25}}$

where, $R_{\mathrm{N}}$ is the normalized fluorescence anisotropy, $R_{T}$ represents the fluorescence anisotropy obtained at different temperatures and $R_{25}$ is the fluorescence anisotropy obtained at $25^{\circ} \mathrm{C}$.

As expected, the fluorescence anisotropy results obtained for pea and soy proteins show that the higher the temperature the higher the unfolding state of the molecules (lower fluorescence anisotropy). Still, when applied at different temperatures, fluorescence anisotropy allowed distinguishing between the gelling ability of these proteins isolates. According to the results presented in Fig. 8, it is possible to conclude that the more significant decrease of fluorescence anisotropy observed for the soy protein, is related to the high unfolding state achieved during heating. In fact, the molecular 
unfolding permits a higher exposure and availability of the binding sites present in the molecule, enabling large intermolecular interactions [25], thus favouring the formation of stronger gel structures, by increasing the ability of the proteins to gellify, as observed for soy and pea proteins. In contrast, significant changes in lupin fluorescence anisotropy were not identified, evidencing the reduced ability of the lupin protein molecule to unfold, and explains the weak gel structure obtained with this protein isolate. The resistance of lupin protein to molecular unfolding is the consequence of its higher structural stability. Moreover, these results constitute a strong evidence that the thermal treatment applied was not sufficient to disrupt intramolecular interactions. Consequently the molecular unfolding of lupin protein is minor, and its binding sites are less exposed, reducing its ability to aggregate (intermolecular interactions).

Moreover, any additional increment of the molecular unfolding state of pea or soy proteins was not detected, at temperatures above $70^{\circ} \mathrm{C}$. This constitutes an evidence that the maximum unfolded state for both proteins was reached at $70^{\circ} \mathrm{C}$, i.e. the maximum exposure of the binding sites present (e.g. free cysteines) in the protein chains was reached.

These results lead us to believe that the gelling process can be accomplished with identical success at temperatures above $70^{\circ} \mathrm{C}$. Nevertheless it should be considered that the concentrations of the protein suspensions used in fluorescence experiments $(0.05 \%, \mathrm{w} / \mathrm{w})$ are much lower than the concentrations needed for proteins to gellify (above $10 \%, \mathrm{w} / \mathrm{w})$. Consequently, for higher protein concentrations, a temperature of $70^{\circ} \mathrm{C}$ might be insufficient to reach the maximum unfolded state, and the mechanical properties of the gels could be enhanced by thermal treatment $[10,12]$.

However, some authors [26] state that it is possible to maintain an identical value of the effective molecular collisions at lower temperatures, by conducing the gelling process under higher pressures, or simply by increasing the processing time, i.e. the time that the proteins are exposed to heating.

The macroscopic rheological and textural properties of globular protein gels (soy, pea and lupin protein isolates) were enlightened by using techniques, such as capillary viscometry, steady-state fluorescence and fluorescence anisotropy, which are sensitive to the proteins structural conformation. These techniques enabled the monitoring of structural changes, of protein molecules, induced by the thermal treatment applied during the gelling process.

The high gelling ability of soy, evidenced by the rheological and textural measurements performed, was associated to the higher unfolding grade observed for this protein isolate, during and after thermal treatment, leading to the formation of a strong gel structure. On the opposite, the lupin protein isolate, probably due to its higher denaturation temperature $[24,27]$, did not unfold significantly at temperatures up to
$90{ }^{\circ} \mathrm{C}$. Actually, the formation of a similar weak gel structure was only possible at higher protein concentrations (above $16 \%)$. Accordingly, the lupin gel obtained did not show significant variations of its viscoelastic functions $\left(G^{\prime}, G^{\prime \prime}\right)$ upon cooling.

\section{Acknowledgments}

This work is part of the research project "Vegetable proteins in foods as an alternative to dairy desserts" sponsored by Fundação para a Ciência e a Tecnologia (Reference POCTI/AGR/38251/2001) and CIERT of Instituto Piaget. Carla A.M. Portugal acknowledges the research grant PRAXIS XXI/BD/19817/99 from Fundação para a Ciência e a Tecnologia. The authors acknowledge Eng. Cristiana Nunes (CERTA - Instituto Piaget de Mirandela) for technical support and Professor António Maçanita for the access to the spectrofluorometer used for fluorescence anisotropy measurements.

\section{References}

[1] H. Bollinger, Food Marketing Technol. 15 (2001) 10-15.

[2] V.B. Tolstoguzov, in: S.E. Hill, D.A. Ledward, J.R. Mitchell (Eds.), Functional Properties of Food Macromolecules, Aspen, USA, 1998.

[3] A. Raymundo, J. Empis, I. Sousa, Z. Lebensm Unters Forsch. 207 (1998) 91-96.

[4] A. Raymundo, J. Empis, I. Sousa, J. Food Eng. 36 (1998) 445-452.

[5] J.M. Franco, A. Raymundo, I. Sousa, C. Gallegos, J. Agric. Food Chem. 46 (1998) 3109-3115.

[6] A. Raymundo, J.M. Franco, P. Partal, I. Sousa, C. Gallegos, JSD_AOCS. 4 (1999) 545-551.

[7] A. Raymundo, J.M. Franco, J. Empis, I. Sousa, J. Am. Oil Chem. Soc. 79 (2002) 783-790.

[8] A. Raymundo, J. Empis, I. Sousa, in: P.A. Williams, G.O. Phillips (Eds.), Gums and Stabilisers for the Food Industry, 10th ed., Royal Society of Chemistry, UK, 2002, pp. 351-365.

[9] M.C. Nunes, P. Batista, A. Raymundo, M.M. Alves, I. Sousa, Colloids Surf. B: Biointerfaces 31 (2003) 21-29.

[10] M.C. Nunes, A. Raymundo, I. Sousa, in: P.A. Williams, G.O. Phillips (Eds.), Gums and Stabilisers for the Food Industry, 12th ed., Royal Society of Chemistry, UK, 2004, pp. 54-64.

[11] A.M. Hermansson, J. Am. Oil Chem. Soc. 63 (1986) 658-666.

[12] J.D. Ferry, Adv. Protein Chem. 4 (1948) 1-78.

[13] C.H. Wang, S. Damoradan, J. Agric. Food Chem. 39 (1991) 433-438.

[14] J.M.S. Renkema. Formation, structure and rheological properties of soy protein gels. Ph. D. thesis, Wageningen University, The Netherlands, 2001. ISBN: 90-5808-501-5.

[15] I.M.N. Sousa, P.J. Morgan, J.R. Mitchell, S.E. Harding, S.E. Hill, J. Agric. Food Chem. 44 (1996) 3018-3021.

[16] J.R. Lakowicz, Principles of Fluorescence Spectroscopy, Plenum Press, New York, 1983.

[17] M.C. Nunes, A. Raymundo, M.M. Alves, I. Sousa, Proceedings of the third National Meeting of Portuguese Society of Rheology, Mirandela, Portugal, 2001, pp. 53-59.

[18] S. Wu, J. Polym. Sci. 27 (1989) 723-741.

[19] N. Loren, M. Langton, A.M. Hermansson, Food Hydrocolloids 13 (1999) 185-198. 
[20] J.A.L. Silva, M.P. Gonçalves, M.A. Rao, J. Biol. Macromol. 17 (1995) 25-32.

[21] C. Rha, P. Pradipasena, in: J.R. Mitchell, D.A. Ledward (Eds.), Functional Properties of Food Macromolecules, Elsevier Applied Science Publishers, London, UK, 1986, pp. 79-120.

[22] C.A. Tanford, J. Phys. Chem. 59 (1955) 798-799.

[23] C.A. Tanford, Adv. Protein Chem. 23 (1968) 121-282.
[24] I.M.N. Sousa, J.R. Mitchell, D.A. Ledward, S.E. Hill, M.L. Beirão da Costa, Z. Lebensm Unters Forsch. 201 (1995) 566-569.

[25] P. Puyol, M.D. Perez, J.M. Peiro, M. Calvo, J. Dairy Sci. 77 (1994) 1494-1502.

[26] S. Funtenberger, E. Dumay, J.C. Cheftel, J. Agric. Food Chem. 45 (1997) 912-921.

[27] R. Cai, A. McCurdy, B.-K. Baik, J. Food Sci. 67 (2002) 1725-1730. 